\title{
NOTE ON TRANSLITERATIONS AND CONVENTIONS
}

For ease and elegance, I have eschewed the use of technical diacritical marks for proper names and for Persian, Arabic, Hindi, Urdu, and Sanskrit words. In most cases, I transliterate these in a manner approximating their pronunciation in South Asia. For specialists, the relevant terms and phrases can be reconstructed generally with little ambiguity. Today, Dara Shukoh's name is most commonly transliterated and pronounced as "Dara Shikoh." However, "Dara Shukoh," which I employ here, more accurately reflects the name in seventeenth-century usage during the prince's lifetime. I do retain "Mughal" for the dynasty to which Dara Shukoh belonged. Though anachronistic, the term for the great Indian dynasty is enmeshed in our historical vocabulary for the period. 

The Emperor Who Never Was 


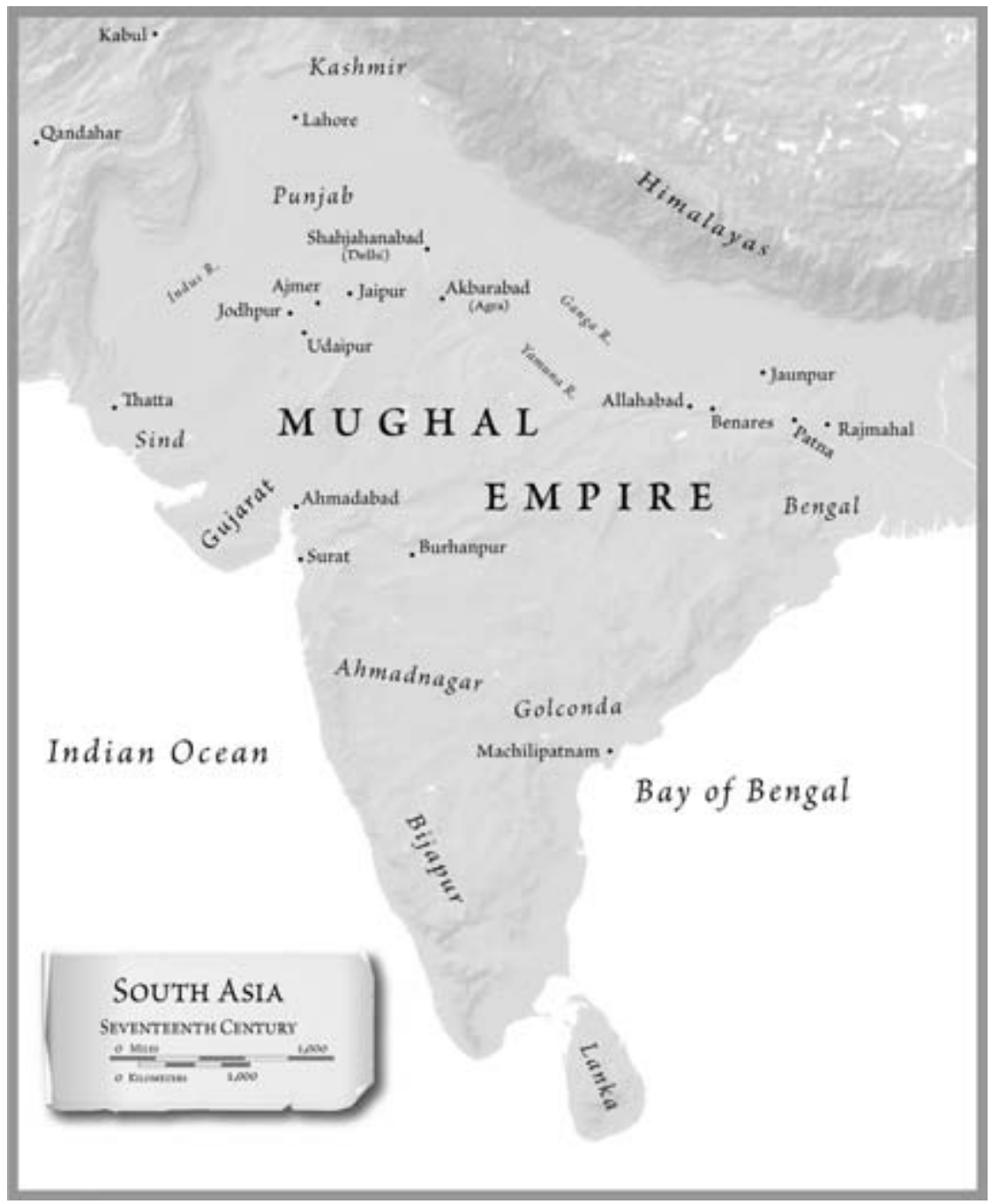

